\title{
BMJ Open Multivariate analysis of biopsychosocial determinants of professional activity among patients after kidney or liver transplantation in Poland
}

\author{
Katarzyna Wesolowska-Gorniak, ${ }^{\oplus 1}$ Monika Wojtowicz, ${ }^{2}$ Jacek Gierus, ${ }^{3}$ \\ Elzbieta Wlodarczyk, ${ }^{4}$ Magdalena Federowicz, ${ }^{5}$ Bozena Czarkowska-Paczek ${ }^{1}$
}

To cite: WesolowskaGorniak K, Wojtowicz M, Gierus J, et al. Multivariate analysis of biopsychosocial determinants of professional activity among patients after kidney or liver transplantation in Poland. BMJ Open 2019;9:e029501. doi:10.1136/ bmjopen-2019-029501

- Prepublication history for this paper is available online. To view these files, please visit the journal online (http://dx.doi org/10.1136/bmjopen-2019029501).

Received 29 January 2019 Revised 9 April 2019 Accepted 31 May 2019

Check for updates

(C) Author(s) (or their employer(s)) 2019. Re-use permitted under CC BY-NC. No commercial re-use. See rights and permissions. Published by BMJ.

For numbered affiliations see end of article.

\section{Correspondence to}

Dr Katarzyna Wesolowska-

Gorniak;

katarzyna.wesolowska@wum. edu.pl

\section{ABSTRACT}

Objective The aim of the present study was to assess the employment rate among kidney and liver transplant recipients in Poland and identify the predictors of employment.

Settings The study was based on a self-prepared questionnaire containing five parts: demographic data and professional, medical, physical and psychological factors. This is a multicentre study involving four hospitals in Poland.

Participants The investigated group consisted of 285 individuals (92 women and 185 men; 8 no sex given) aged between 18 and 45 years who underwent kidney or liver transplantation 1-5 years prior. Because of missing data, 279 questionnaires were considered regarding employment status after transplantation and 277 when sex differences were considered.

Results A total of 120 patients (43\%) worked full-time, 42 (15\%) part-time and 117 (42\%) remained unemployed, with a higher employment rate post-transplantation among men than women ( $60 \%$ vs $55 \%, p=0.04$ ). More women performed white collar work ( $74 \%$ vs $41 \%$, $\mathrm{p}=0.0003$ ) and had to modify their working position than men ( $22 \%$ vs $7 \%, p=0.0118$ ). Factors determining employment after transplantation included higher level of education ( $\mathrm{OR}=27.08 ; \mathrm{p}=0.0096)$, employment 1 year prior to transplantation $(0 R=11.05 ; p<0.001)$ and good psychological adaptation $(0 R=4.23 ; p<0.001)$. Men working the year before transplantation had higher education ( $0 R=9.66 ; p=0.0356$ ). Among men, more kidney recipients worked compared with liver recipients $(\mathrm{OR}=3.567 ; \mathrm{p}=0.0417)$. Among women, age determined employment status $(0 R=0.89 ; p=0.0234)$.

Conclusion Higher education is the most important predictor of employment after transplantation. Therefore, rehabilitation programmes including vocational activity should be directed to increase the level of education, both pretransplantation and post-transplantation if possible.

\section{INTRODUCTION}

Developments in medical and surgical therapies, including solid organ transplantation, have resulted in increased survival of transplant organ recipients. In addition, the
Strengths and limitations of this study

- This study is a multicentre study involving four hospitals in Poland receiving patients from whole country.

- The cohort is representative of the first-time (from 1 to 5 years) kidney or liver transplantation, taking into account the fact that only patients of working age were included in the study.

- This is a first study adopting a biopsychosocial model, linking a psychosocial questionnaire with medical and physical data in Poland, which allowed us to analyse predictive factors of the employment status after transplantation.

- Disproportion between number of patients after kidney and liver transplantation can be considered as a limitation; nevertheless, the both study groups were large enough to perform statistical analysis.

- The age of the respondents may be perceived as a limitation of this study; however, according to the research team, this is an advantage because age range was chosen deliberately to enable the respondents to take action if the factors determining employment turned out to be modifiable.

number of transplantations performed every year has increased, with the number of recipients increasing worldwide. The short-term survival rate in liver transplant recipients is currently $\sim 90 \%$, and long-term life expectancy in these patients could exceed 20 years. ${ }^{1}$ The 10-year survival rate of kidney transplant recipients varies between countries, from $43 \%$ to $59 \% .^{2}$ In Poland, the 10 -year survival rates for kidney and liver transplant recipients are $74 \%$ and $65 \%$, respectively. ${ }^{34}$ In Poland, the social security system covers the cost of specialist medical care and immunosuppressant drugs for life. Thus, the goal of current holistic care for transplant organ recipients is survival and prolonging life, and complete rehabilitation, including full re-integration, 
good quality of life and return to social and vocational life.

Previous studies indicate that many patients remain unemployed after kidney or liver transplantation. The rate of employment among these patients is lower than in the general population and varies between countries, from $18 \%$ to $82 \%$ after kidney transplantation and between $22 \%$ and $55 \%$ after liver transplantation. ${ }^{15}$ These discrepancies may be due to the definition of work lacking standardisation; the investigated groups varying in terms of age, education and previous vocational experience; the different social security programmes in particular countries, which deeply influence the rate of unemployment; the year of investigation, as the surgical techniques and pharmaceuticals have changed over the years and local sociocultural conditions.

The advantages of being employed depend on the perspective. ${ }^{1}$ From the patients' point of view, employment is the source of income associated with self-fulfilment, satisfaction and better psychological adaptation. Having an income increases independence and, in many cases, the position in the family and neighbourhood. It has also been shown that vocational activity positively influences the condition of the graft in the case of kidney transplantation and heart transplantation. ${ }^{67}$ From doctors' perspective, the employment status of the patient could serve as a surrogate indicator of therapy outcome. From the third perspective, that of the country's healthcare system and economy, transplantation procedures and subsequent unemployment are associated with direct and indirect costs, with the latest resulting from the loss of productivity, especially as most transplant recipients are working age at the time of transplantation.

Kidney or liver transplantation does not imply complete health normalisation, and patients have many work limitations after receiving a transplant. Therefore, complex rehabilitation should be implemented in every case, including vocational rehabilitation, but the current local situation and conditions should be evaluated before any vocational rehabilitation programmes, which should be based on the results.

The purpose of this study was to assess the employment rate among kidney and liver transplant recipients in Poland and to identify predictors of employment.

\section{METHODS \\ Patients}

The investigated group consisted of 285 kidney or liver transplant recipients (92 women and 185 men) aged between 18 and 45 (mean $35.7 \pm 7.43$ ) years (8 respondents did not indicate their sex). All of the patients underwent transplantation 1-5 years prior. The age range of the participants was established to select those of working age. The investigated group comprised 214 kidney transplant patients and 69 liver transplant patients; for two cases no such data were available. Because of missing data, 279 questionnaires were considered regarding employment status after transplantation and 277 when sex differences were considered.

\section{Patient and public involvement}

As part of the study, a group of patients after liver or kidney transplantation were consulted in correctness and understanding of the research tool (questionnaire). The patients were neither directly involved in the design of the study nor in the recruitment and carrying out of the study. The authors intend to disseminate results to study participants through written summaries transmitted to them by the State Fund for Rehabilitation of Disabled People in Poland.

\section{Measures}

This study used a cross-sectional survey design in which participants completed the questionnaire on one occasion. All questions used in the questionnaire were author-derived. The questionnaire was built using a biopsychosocial model and contained five parts: sociodemographic data, professional factors, medical factors, physical factors and psychological factors. Physical factors were evaluated using a 5-point Likert scale and were summed, resulting in a range of 7-35, with higher values interpreted as inferior physical fitness. Psychological factors were evaluated in the last part of the questionnaire using the 5-point Likert scale and interpreted as 'post-transplantational adaptation'. Scores were converted to sten scores, where 1 was considered 'very low post-transplantational adaptation' and 10 as 'very high post-transplantational adaptation'. The detailed questions included in the questionnaire are presented in figure 1.

The investigation was performed between February and September 2018 in the outpatient clinics of the Department of Immunology, Transplantology, and Internal Diseases and Department of Transplantology and General Surgery, Medical University of Warsaw, Collegium Medicum in Bydgoszcz, Nicolaus Copernicus University and the Department of Transplantology and General Surgery in Provincial Hospital in Poznan. Each patient received a cover letter explaining the purpose of the study and ensuring confidentiality. The names of responders were not recorded on the questionnaire, rendering the data anonymous. Informed consent was
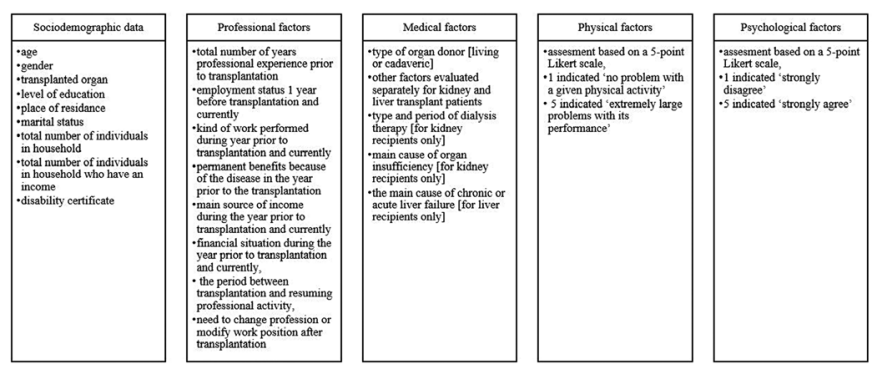

Figure 1 The detailed questions included in the questionnaire. Multivariate regression logistic analysis of the factors influencing employment status among patients after renal or kidney transplantation. 
indicated by voluntary participation in the survey. The questionnaire was completed under previous instruction by the investigators.

\section{Social benefits system in Poland}

The average salary in 2018 in Poland was PLN 4585.03 (EUR 1073), while the average amount of disability pension in 2018 amounted to PLN 1654.88 (EUR 387). The Polish system of jurisprudence does not prohibit employment by persons receiving a disability pension without losing this benefit. ${ }^{89}$

\section{Statistical analysis}

Data collected from the questionnaires were calculated using R package V.3.5.1. Logistic regression modelling was performed in StatSoft STATISTICA V.13.1. Continuous variables were described by median, first and third quartile, minimum, maximum and arithmetic mean with $\mathrm{SD}$, whereas categorical variables were presented as count and percentage.

The non-parametric Mann-Whitney $\mathrm{U}$ test was used to compare continuous variables between two groups of observations, and the Kruskal-Wallis test was used for three or more groups. These tests were also used for the psychological part of the questionnaire (variable on an ordinal scale).

To detect significant relationships between categorical variables, Pearson's $\mathrm{X}^{2}$ test or Fisher's exact test was used and the value of power test analysis was $>0.8$.

Multivariate analysis was performed using logistic regression. $\mathrm{P}$ value $\leq 0.05$ was considered to be statistically significant. The regression model of factors determining employment after transplantation was built from all sociodemographic, professional, physical and psychological factors. The medical factors were considered separately.

To analyse psychological predictors of unemployment after transplantation, logistic regression was performed.
Initial analyses (LR significance and forest plots) excluded most variables. Further analyses contained logit probability and v-cross validation. The prediction of unemployment was conducted with use of $\mathrm{X}^{2}$ test. Significance of the model and its goodness of fit were tested with Wald, Hosmer-Lemeshow and Nagelkerk tests.

\section{RESULTS \\ Characteristics of the study population}

According to this survey study, in the whole investigated group ( $\mathrm{n}=279), 120$ patients worked full-time $(43 \%), 42$ part-time (15\%) and 117 did not work (42\%). Among all unemployed, health reasons $(69 \%)$ are given as the main reason for not taking up employment, followed by the intention to continue education $(11 \%)$ and fear of losing disability benefits $(9 \%)$. Incorrect data were recorded in $11 \%$ of cases. The total employment rate post-transplantation was higher among men than women $(60 \%$ vs $55 \%, \mathrm{p}=0.04)$. More women than men performed white collar work ( $74 \%$ vs $41 \%, \mathrm{p}=0.0003$ ) and had to modify their working position ( $22 \%$ vs $7 \%, \mathrm{p}=0.0118$ ). No significant differences were found between women and men in regard to the other professional factors (figure 1). The relationships between categorical variables between employed and unemployed before and after transplantation are shown in table 1.

\section{Predictors of employment after transplantation}

Multivariate regression logistic analysis revealed that the main factors influencing current employment status among patients post-transplantation were the level of education, employment status the year prior to transplantation and psychological adaptation post-transplantation. The influence of other variables on employment status

Table 1 The relationships between employment status before and after transplantation and place of resistance and marital status

\begin{tabular}{|c|c|c|c|c|c|c|}
\hline & \multicolumn{2}{|c|}{$\begin{array}{l}\text { Employment status during } \\
1 \text { year before transplantation }\end{array}$} & \multirow[t]{2}{*}{$\begin{array}{l}\text { Test } \\
\text { (p value) }\end{array}$} & \multicolumn{2}{|c|}{$\begin{array}{l}\text { Employment status after } \\
\text { transplantation }\end{array}$} & \multirow[t]{2}{*}{$\begin{array}{l}\text { Test } \\
\text { (p value) }\end{array}$} \\
\hline & Yes & No & & Yes & No & \\
\hline Villages and smaller towns & $\begin{array}{l}n=56 \\
(20 \%)\end{array}$ & $\begin{array}{l}n=82 \\
(29 \%)\end{array}$ & & $\begin{array}{l}n=65 \\
(23 \%)\end{array}$ & $\begin{array}{l}n=70 \\
(25 \%)\end{array}$ & $\begin{array}{l}X^{2} \\
(<0.001)\end{array}$ \\
\hline Marital status & \multicolumn{2}{|c|}{$\begin{array}{l}n=277 \\
\text { missing data } n=8(3 \%)\end{array}$} & $\begin{array}{l}\text { Fisher's } \\
(<0.001)\end{array}$ & \multicolumn{2}{|c|}{$\begin{array}{l}n=275 \\
\text { missing data } n=10(4 \%)\end{array}$} & \multirow[t]{2}{*}{$\begin{array}{l}\text { Fisher's } \\
(0.023)\end{array}$} \\
\hline Formal and informal relationship & $\begin{array}{l}n=128 \\
(45 \%)\end{array}$ & $\begin{array}{l}n=61 \\
(21 \%)\end{array}$ & & $\begin{array}{l}n=120 \\
(42 \%)\end{array}$ & $\begin{array}{l}n=68 \\
(24 \%)\end{array}$ & \\
\hline
\end{tabular}

Villages and smaller towns ( $<20000$ inhabitants); medium and larger towns ( $>20000$ inhabitants). 


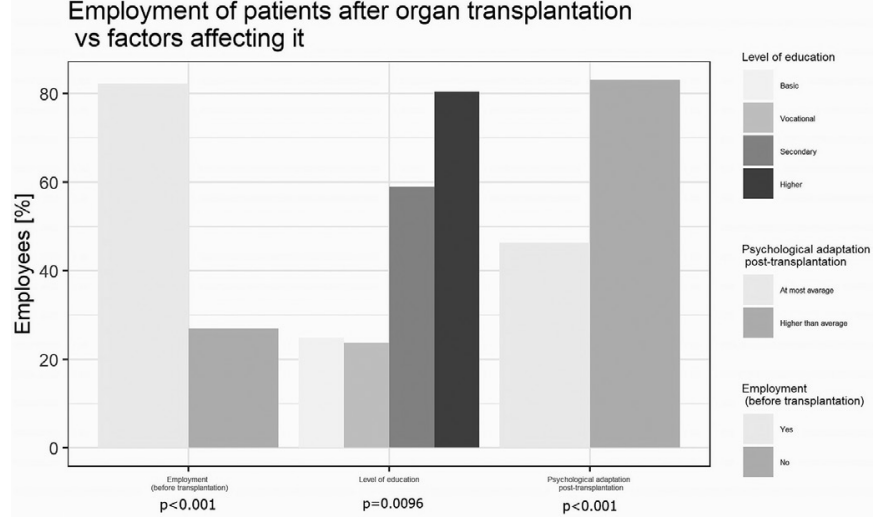

Figure 2 Multivariate regression logistic analysis of factors influencing post-transplantation employment status.

after transplantation was not demonstrated. Those results are presented in figure 2 .

The same model was built separately in men and women and they revealed that employment 1 year prior to transplantation increased the chance for post-transplantation employment in both groups, the psychological adaptation and higher education increased this chance only in the group of men and age (each year) decreased this chance in woman. In addition, men had a greater chance of post-transplantation employment after kidney transplantation than liver transplantation. Those results are presented in figures 3 and 4 .

In the group of patients working the year prior to transplantation, those who performed white collar work had greater chance of post-transplantation employment, and among men from the same group the highest chance for employment post-transplantation was found for those with higher education.

The detailed results of regression logistic analysis of above models are presented in table 2 .

\section{Predictors of unemployment after transplantation}

In the selected $(n=220)$ observations, logistic regression excluded employment before transplantation as a predictor of unemployment after transplantation. Further analyses revealed 'post-transplantation adaptation'

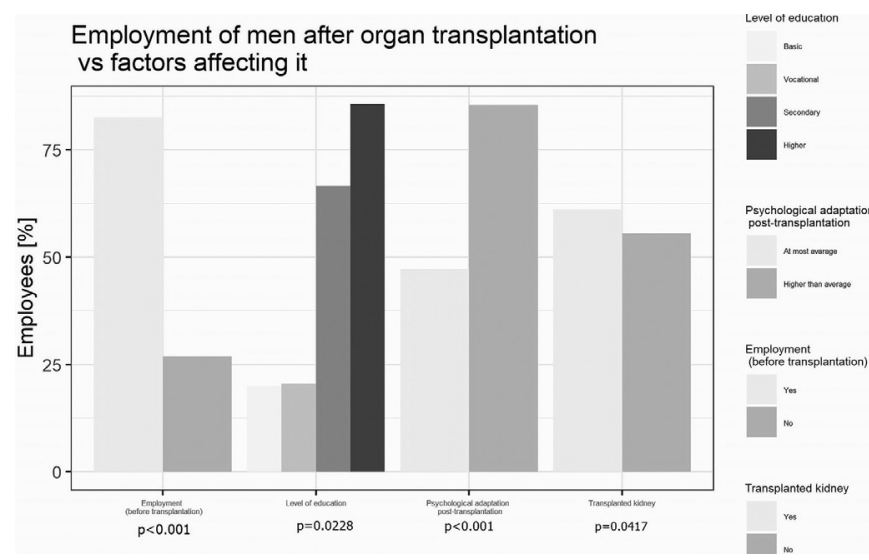

Figure 3 Multivariate regression logistic analysis of factors influencing post-transplantation employment status in men.

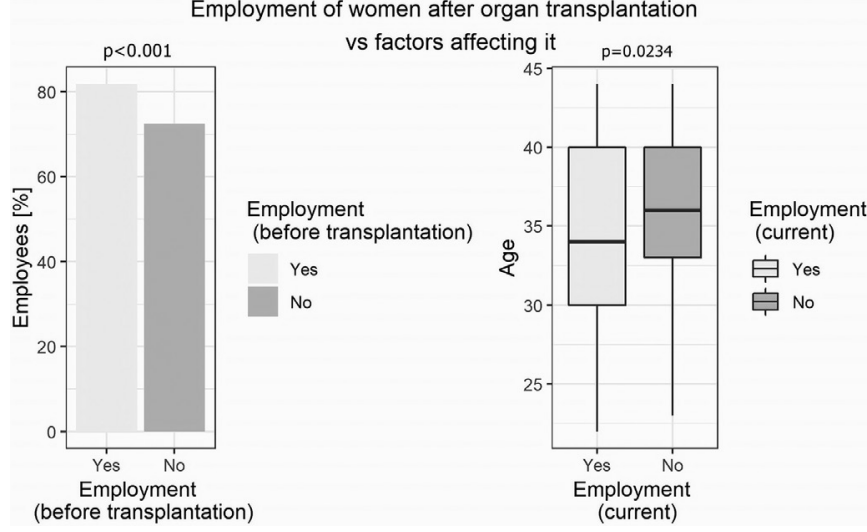

Figure 4 Multivariate regression logistic analysis of factors influencing post-transplantation employment status in women.

and two qualitative variables (confirming question: 'my present health state is unbearable', confirming physical job before transplantation) were potential good predictors of unemployment after transplantation. Post-transplantation unemployment was well predicted by:

1. low scores in 'post-transplantation adaptation' $\left(\mathrm{X}^{2}=15.637, \mathrm{p}=0.000, \mathrm{df}=1\right)$;

2. physical job before transplantation $\left(X^{2}=81.372\right.$, $\mathrm{p}=0.000, \mathrm{df}=5)$;

3. sense of individual health state is being unbearable $\left(\mathrm{X}^{2}=12.763, \mathrm{p}=0.012, \mathrm{df}=4\right)$.

The Wald test revealed the significance of model parameters $(p=0.000)$. The model demonstrated satisfactory goodness of fit (Hosmer-Lemeshow=10.6435, $\mathrm{p}=0.222$; Akaike Information Criterion (AIC) $=250.217$; Bayesian Information Criterion $(B I C)=290.169$; Cox-Snell $\mathrm{R}^{2}=0.376$; Nagelkerk $\left.\mathrm{R}^{2}=0.509\right)$. The area under the curve (AUC) for the model was 0.87 (AUC error=0.02), which indicates satisfactory sensitivity and specificity.

\section{Other factors}

Medical factors from the questionnaire were analysed separately in the group of patients with kidney or liver transplantation. Patients with end-stage kidney disease (ESKD) resulting from diabetes had 5-times lower chances of employment after kidney transplantation than patients with other reasons for $\mathrm{ESKD}(\mathrm{OR}=0.183$, $\mathrm{p}=0.0132)$. In the case of patients with liver transplantation, a regression logistic analysis model was not possible.

\section{DISCUSSION}

Transplantation is a medical procedure that prolongs patients' life expectancy, and improves quality of life and work ability. Nevertheless, many patients do not work after solid organ transplantation, despite the lack of contraindications in many cases and obvious benefits associated with being employed.

The Polish system of jurisprudence allows patients with a disability certificate to work part-time or full-time. In the present study, $58 \%$ of patients worked full-time or 
Table 2 Multivariate regression logistic analysis of factors influencing employment status after transplantation

\begin{tabular}{|c|c|c|c|}
\hline & OR & $95 \% \mathrm{Cl}$ & $P$ value \\
\hline \multicolumn{4}{|l|}{ Whole study group } \\
\hline Higher education & 27.08 & 3 to 635.6 & $<0.01$ \\
\hline Medium or good psychological adaptation & 4.23 & 1.9 to 10.1 & $<0.001$ \\
\hline \multicolumn{4}{|l|}{ Men } \\
\hline Employment 1 year prior to transplantation & 18.62 & 6.5 to 64.3 & $<0.001$ \\
\hline Medium or good psychological adaptation & 9.79 & 1.8 to 716.3 & $<0.001$ \\
\hline Patients after kidney transplantation & 3.57 & 1.1 to 12.9 & 0.042 \\
\hline \multicolumn{4}{|l|}{ Woman } \\
\hline Employment 1 year prior to transplantation & 17.48 & 5.8 to 63.7 & $<0.001$ \\
\hline White collar work & 3.97 & 1.2 to 15.4 & 0.028 \\
\hline \multicolumn{4}{|l|}{ Men employed during 1 year prior transplantation } \\
\hline Higher education & 9.66 & 1.7 to 182.9 & 0.0356 \\
\hline
\end{tabular}

part-time, which is close to the employment rates from other studies conducted in groups of post-transplantation patients in other countries. ${ }^{5} 1011$ However, these results differ from the results obtained in a previous Polish study by Ostrowski et $a l^{12}$ in which the employment rate after kidney transplantation was much higher; $63.75 \%$ of patients worked part-time and $10 \%$ had a full-time job. The discrepancies between the results may be due to the smaller research sample in the study by Ostrowski et al $(n=80)$ or different definition of 'employment', which was not clearly explained in that study.

In the present study, we observed many significant differences between males and females. First, the employment rate was higher among men than women. Male sex was a consistent univariate predictor of employment in a few other studies. In the study by Huda et al, females were 0.57-times less likely than males to be employed after liver transplantation. ${ }^{13}$ Female sex was also negatively associated with post-transplantation employment status in the studies by Weng et al and De Baere et al. ${ }^{14} 15$ Åberg's review focused on studies published after 2000 showed heterogeneity in the influence of sex on employment status. Among all analysed studies, sex had a significant impact on employment in only three of them. ${ }^{1}$ This may be explained by discrepancies in definitions, in which working was considered to be synonymous with employment. In the present study, employment was considered to be income-producing work and was clearly indicated in the questionnaire. In the present study, sex differentiated the type of profession performed by post-transplant patients. Women were more likely to perform white collar work, and they more often had to modify their work position. This is in line with the general distribution of employment in Poland. Statistics show that the most feminised professional groups are office workers, specialists, education and healthcare workers. The highest percentage of employed men is in sectors such as construction, mining and industry. ${ }^{16}$ The type of work performed by patients after transplantation was not extensively examined in the other studies. In the study by Nour et al, participation in jobs involving physically demanding work significantly decreased $(\mathrm{p}=0.02)$ from pretransplantation to post-transplantation, and participation in sedentary work increased post-transplantation, but this was not considered based on sex. ${ }^{17}$ Considering the need to modify the workplace for the safety of the transplanted organ, white collar workers are relatively rarely exposed to hazards, such as infections. Individualised occupational counselling may be important for transplant recipients contemplating a return to work in areas such as healthcare, construction, outdoor work and other fields. For these professions a few guidelines exist, but the vast majority of jobs can be made safer by simple measures such as restricting patient contact for the initial phase of returning to work in a healthcare environment, wearing masks when there are potential exposures to fungal spores, respiratory viruses or other transmissible illnesses and sometimes reassignment to other duties, particularly during periods of intensified immunosuppression. Coworkers are often encouraged to receive influenza vaccinations to help protect the recipient as well. $^{18}$

For women, the chance to get a job after solid organ transplantation decreases with age. This result is consistent with other studies. In Åberg's study, $>80 \%$ of liver recipients aged 20-29 years were able to resume work, whereas only $30 \%$ of recipients $>50$ years of age were able to resume work. ${ }^{19}$ In the group of men, the important factor determining employment after transplantation was 
the transplanted organ. Kidney patients being more likely to be employed after transplantation than non-kidney patients was also observed in other studies. ${ }^{10}{ }^{11}$ Some authors indicated that the possible cause of this is longer experience with kidney transplantation compared with liver, heart or lung transplantation, or more complications observed in non-kidney recipients after surgery, hindering them from work. ${ }^{10} 1520$

In the present study, the place of residence of recipients differentiated professional factors. Patients living in medium-sized and larger-sized towns more often worked before and after transplantation than patients living in smaller towns and villages. The place of residence has rarely been considered in other studies as a factor that can determine employment after transplantation. The results of our study indicate that, in larger towns, the offer and access to work is greater, which may influence the professional factors evaluated by our questionnaire. Data from studies performed in different regions in the USA have shown variation that seems to be attributable to local economic conditions. The highest employment rates in patients after liver transplantation were observed in states with growing economies. ${ }^{21}$

In both the available literature and the present study, marital status differentiates professional activity and associated factors. In our study, more single patients remained unemployed post-transplantation and lived on the benefits due to disease compared with patients with a different marital status. In the study by Nour et al, patients who were not working after kidney transplantation were more likely to be living on their own than patients who returned to work post-transplant. ${ }^{17}$ Living with others or being in a formal or informal relationship may facilitate environmental factors that support the behaviour of participation in paid work after transplantation.

Our research allowed us to identify determinants of post-transplantation employment. Higher education was the strongest employment predictor in this study. One of the reasons may be that average salary for work performed by people with higher education significantly exceeds the amount of the disability pension, while the average salary received by people with basic education is close to the amount of the benefit. ${ }^{22}$ Level of education was considered an important factor determining employment in other studies. ${ }^{13}{ }^{17}$ In the study by Huda et al, patients with a college degree were 1.92-times more likely to be employed than patients who did not complete higher education. ${ }^{13}$ This is a very important result because it shows that there are still some modifiable factors that should be considered in constructing vocational and educational rehabilitation programmes for patients, both pretransplantation and post-transplantation.

Pretransplant employment status is also a consistent predictor of employment after transplantation in our and other recent studies. ${ }^{10}{ }^{13}$ Patients who have been out of the workforce for long periods have difficulty returning to work. Financial and social support during the disability period is not motivating for returning to work. For more detailed analysis of factors that can determine employment after transplantation, an analogic regression model was built, but only in groups of patients who were working the year prior to transplantation. This analysis confirmed the role of higher education and type of work, for example, white collar work, which is mainly performed by people with higher education.

The education level and pretransplantation employment may be affected by long-term chronic organ failure. It is quite difficult for a patient to work full-time or attend school when in a dialysis programme, or when they have advanced liver disease with symptoms such as fatigue, hepatic encephalopathy, impaired mobility or ascites and oedema. Higher education and higher income are associated with higher life expectancy. ${ }^{2324}$ In connection with the above, it seems reasonable to implement rehabilitation programmes for patients with end-stage organ failure as early as possible and include strong educational and vocational considerations and advisory system in this field. Families of such patients often spare them from the effort to attain proper education, but according to the above data, such a situation will be directed against them in the future. Notably, vocational rehabilitation programmes for post-transplantation patients should contain elements that increase their qualifications and education level, and education aimed at employers and different forms of compensation that could redress patients' absence from work.

Unemployment after transplantation may be affected (50\% of variance) by psychosocial factors, such as physical job before transplantation, low score on the post-transplantational adaptation scale and feeling that their present health status is unbearable. It may be difficult for physical workers to adapt to a new situation and physical limitations. Other research has confirmed perceived physical ability or subjective sense of impairment as a predictor of occupational decisions. ${ }^{25}$ Therefore, psychologists should be included on vocational rehabilitation teams. This help should be applied in different ways: for screening and management of depression, and increasing self-efficacy or motivation to voluntarily return to work. ${ }^{117}$

Analysis of medical factors, which was performed separately for patients after liver and kidney transplantation, showed that basic disease can influence the employment status after transplantation. Fewer patients with ESKD due to diabetes mellitus were employed after transplantation compared with patients with other basic diseases. However, end-stage renal failure resulting from diabetes is not the only possible complication. Diabetes is one of the first 10 causes of disability in people around the world. ${ }^{26}$ Manninen et $a l^{27}$ confirmed that patients with or without diabetes differ in their ability to work after kidney transplantation ( $74.4 \%$ vs $34.7 \%)$. The same analysis was not performed in patients who received a liver transplant due to a small investigated group. 


\section{CONCLUSION}

Contemporary transplant medicine allows patients to be employed after transplantation, which could serve as an indicator of treatment outcomes. The employment rate among patients after liver or kidney transplantation in Poland does not differ from the indicators observed in other countries. Poland does not have a national programme for occupational rehabilitation of patients after transplantation. The present study indicates that modifiable factors, such as higher education, employment before transplantation and better psychological adaptation, decide employment after transplantation. Higher education is the most important predictor, which was assessed directly and indirectly. Therefore, rehabilitation programmes including vocational activity should mainly be directed to increase the level of education, both pretransplantation and post-transplantation if possible. Other factors, including local conditions, should also be taken into account. Vocational and educational advisors should be included in multidisciplinary rehabilitation teams and help the patients choose the best pathway for educational and further vocational activity.

\section{Author affiliations}

${ }^{1}$ Department of Clinical Nursing, Medical University of Warsaw, Warsaw, Poland ${ }^{2}$ Department of Immunology, Transplantology, and Internal Diseases, Medical University of Warsaw, Warsaw, Poland

${ }^{3}$ Clinic of Psychiatry, Medical University of Warsaw, Pruszkow, Poland

${ }^{4}$ Department of Geriatrics, Collegium Medicum, Nicolaus Copernicus University in Torun, Bydgoszcz, Poland

${ }^{5}$ Department of Rehabilitation, Central Teaching Clinical Hospital in Warsaw, Warsaw, Poland

Contributors The authors of this paper have directly participated in all the stages of its preparation. KW-G and BC-P conceived and designed the study, analysed, interpreted the data, prepared all the draft versions of the manuscript. MW, EW and MF recruited the participants, collected and interpreted the data and edited and approved the final version of the manuscript. JG designed a part of the study, performed the statistical analysis and interpretation of the data. All authors approved the final version of the manuscript.

Funding The research was financed by the State Fund for Rehabilitation of Disabled People in Poland (No. BEA/000034/BF/D).

Competing interests None declared.

Patient consent for publication Not required.

Ethics approval The Ethics Committee of the Medical University of Warsaw, Poland, approved the experimental protocol (No. KB/7/A/2018).

Provenance and peer review Not commissioned; externally peer reviewed.

Data sharing statement None of the data included in the article or sent as supplementary information include identifiable patient data.

Open access This is an open access article distributed in accordance with the Creative Commons Attribution Non Commercial (CC BY-NC 4.0) license, which permits others to distribute, remix, adapt, build upon this work non-commercially, and license their derivative works on different terms, provided the original work is properly cited, appropriate credit is given, any changes made indicated, and the use is non-commercial. See: http:// creativecommons.org/licenses/by-nc/4.0/.
REFERENCES

1. Åberg F. From prolonging life to prolonging working life: tackling unemployment among liver-transplant recipients. World $J$ Gastroenterol 2016;22:3701-11.

2. Gill JS, Tonelli M. Penny wise, pound foolish? Coverage limits on immunosuppression after kidney transplantation. N Engl J Med 2012;366:586-9.

3. Przygoda J, Borczon S, Łęczycka A, et al. Rejestr przeszczepień narządów. Biuletyn informacyjny, Poltransplant 2017;1:49-52.

4. Czerwiński J, Antoszkiewicz K, Grygiel K, et al. National transplants registry in poland: early and long-term results of organ transplantations in the years 1998 to 2014. Transplant Proc 2016;48:1407-10.

5. Eng M, Zhang J, Cambon A, et al. Employment outcomes following successful renal transplantation. Clin Transplant 2012;26:242-6.

6. Petersen E, Baird BC, Barenbaum LL, et al. The impact of employment status on recipient and renal allograft survival. Clin Transplant 2008;22:428-38.

7. Marcinkowska U, Kukowka K, Gałeczka M, et al. Professional and social activity of patients after heart transplant. Int J Occup Med Environ Health 2015;28:741-9.

8. Website of the polish social security institution. https://www.zus.pl/ baza-wiedzy/skladki-wskazniki-odsetki/wskazniki/emerytury-i-renty (Accessed 29 Mar 2019).

9. Website of the Statistic Poland. https://stat.gov.pl/ (Accessed 29 Mar 2019).

10. Vieux L, Simcox AA, Mediouni Z, et al. Predictors of return to work 12 months after solid organ transplantation: results from the swiss transplant cohort study. J Occup Rehabil 2019;29:462-471.

11. Tzvetanov I, D'Amico G, Walczak D, et al. High rate of unemployment after kidney transplantation: analysis of the United network for organ sharing database. Transplant Proc 2014;46:1290-4.

12. Ostrowski M, Wesołowski T, Makar D, et al. Changes in patients' quality of life after renal transplantation. Transplant Proc 2000;32:1371-4.

13. Huda A, Newcomer R, Harrington C, et al. High rate of unemployment after liver transplantation: analysis of the United Network for Organ Sharing database. Liver Transpl 2012;18:89-99.

14. Weng LC, Huang HL, Wang YW, et al. The effect of self-efficacy, depression and symptom distress on employment status and leisure activities of liver transplant recipients. J Adv Nurs 2014;70:1573-83.

15. De Baere C, Delva D, Kloeck A, et al. Return to work and social participation: does type of organ transplantation matter? Transplantation 2010;89:1009-15.

16. Główny Urząd Statystyczny. Kobiety i mężczyźni na rynku pracy. 2012 https://stat.gov.pl/cps/rde/xbcr/gus/f_kobiety_i_mezczyzni_na_ rynku_pracy_2012.pdf (Accessed 29 Mar 2019).

17. Nour N, Heck CS, Ross H. Factors related to participation in paid work after organ transplantation: perceptions of kidney transplant recipients. J Occup Rehabil 2015;25:38-51.

18. Avery RK, Michaels MG. AST infectious diseases community of practice. strategies for safe living after solid organ transplantation. Am J Transplant 2013;13:304-10.

19. Aberg F, Rissanen AM, Sintonen $\mathrm{H}$, et al. Health-related quality of life and employment status of liver transplant patients. Liver Transpl 2009;15:64-72.

20. Danuser B, Simcox A, Studer R, et al. Employment 12 months after kidney transplantation: An in-depth bio-psycho-social analysis of the Swiss Transplant Cohort. PLoS One 2017;12:e0175161.

21. Huda A, Newcomer R, Harrington C, et al. Employment after liver transplantation: a review. Transplant Proc 2015;47:233-9.

22. Ogólnopolskie badanie wynagrodzeń. $2017 \mathrm{https}: / /$ wynagrodzenia.pl/ artykul/podsumowanie-ogolnopolskiego-badania-wynagrodzen-w2017-roku (Accessed 29 Mar 2019).

23. van Raalte AA, Sasson I, Martikainen P. The case for monitoring lifespan inequality. Science 2018;362:1002-4.

24. Chetty R, Stepner M, Abraham S, et al. The association between income and life expectancy in the United States, 2001-2014. JAMA 2016;315:1750-66.

25. Callahan MB, Paris W. Post-transplant employment and its relationship to physical status in kidney transplant recipients. $J$ Nephrol Soc Work 2009;30:9-15.

26. International Diabetes Federation. A call to action on diabetes, 2010.

27. Manninen DL, Evans RW, Dugan MK. Work disability, functional limitations, and the health status of kidney transplantation recipients posttransplant. Clin Transpl 1991:193-203. 